\title{
Bir dizel gemi jeneratörünün operasyonel modal analizi
}

\author{
Adil YÜCEL* \\ İstanbul Teknik Üniversitesi, Makina Fakültesi, Makina Mühendisliği Bölümü, Gümüşsuyu Kampüsü, \\ Istanbul \\ Geliș Tarihi (Received Date): 02.06.2020 \\ Kabul Tarihi (Accepted Date): 21.07.2020
}

$\ddot{\mathbf{O} z}$

Bu çalışmada, özellikle ikaz kuvvetlerinin belli olmadığ durumlarda, yapıların, çalışma şartlarında modal karakteristiklerinin elde edilmesi amactyla gelişstirilmiş bir deneysel modal analiz yöntemi olan Operasyonel Modal Analiz (OMA) yönteminin bir dizel gemi jeneratör seti üzerinde uygulanması gerçekleştirilmiştir. Çalışmada, modal analizi yapılan jeneratör setinin, kaidelerinden sökülmeden ve herhangi bir ikaz vermeden, çalışma esnasında titreşim zaman veri setleri kaydedilmiş ve güç spektral yoğunlukların tekil değerlere ayrıştırılması yöntemi ile harmonikler ve doğal frekans değerleri elde edilmiştir.

Anahtar kelimeler: Operasyonel modal analiz, jeneratör titreşimleri, gemi titreşimleri.

\section{Operational modal analysis of a marine diesel genset}

\begin{abstract}
In this study, one of the experimental modal analysis methods called Operational Modal Analysis (OMA) which is conducted in order to obtain modal characteristics of a running system when the excitation forces are unknown and the system is in ambient conditions, has been applied on a marine diesel generator set. In the study, the vibration time datasets have been recorded without detaching the genset from the foundations in ambient conditions and the modal frequencies with harmonics have been obtained using the method of singular values decomposition of power spectral densities.
\end{abstract}

Keywords: Operational modal analysis, genset vibrations, ship vibrations.

*Adil YÜCEL, adil.yucel@itu.edu.tr, http://orcid.org/0000-0003-2384-2473 


\section{Giriş}

Günümüzdeki gemiler, içerisinde birçok mekanik ve elektronik ekipman bulunduran kompleks yapılardır. Teknolojinin gelişmesiyle yapılan çalışmalar artmış, bu çalışmalar gemi sektöründe de etkilerini göstermiştir. Deniz taşımacılığına günden güne artan talep, gemi inşaatı ve gemi makinaları sektörünü pozitif yönde ivmelenen bir rekabet alanı haline getirmiştir. Bu talebin karşılanması için yapılan yeni tasarımlarda gemiler giderek hızlandırılmakta, hafifletilmekte ve boyutları büyütülmektedir. Bu tasarımların gemide emniyet ve konfor kriterlerinin gözetilerek oluşturulmasında, titreşim ve akustik analizler büyük önem arz etmektedir. Gemilerde titreşimin iç ve dış kaynaklar olmak üzere iki temel unsuru vardır. Ana makina, jeneratörler, pervane şaftı vb. gibi unsurlar iç kaynaklara örnek olarak verilebilirken dalga, rüzgâr, akıntı veya gemideki dengesiz yükleme durumları dış kaynaklara örnek verilebilir. İstenmeyen bu titreşimler, gemilerde büyük hasarlara neden olabilmektedir. Yolcu ve personelin seyahat kalitesi ve güvenliği ile çalışan ekipmanların performansı, oluşan titreşimlerden oldukça etkilenmektedir. A ğır yıkıcı sonuçlara dahi sebep olabilen titreşim problemi, gemide tasarım aşamasında öncelik verilmesi gereken konulardan biridir [1]. Bu çalışmada, yerel titreşim kaynaklarının en önemlilerinden biri olan gemi jeneratörlerinin, işletme şartlarında yapılan ve "Operasyonel Modal Analiz (OMA)" olarak adlandırılan modal analiz yöntemi ile doğal frekans ve mod şekillerinin elde edilmesi gerçekleştirilmiştir. Çalışmanın sonucunda, analizin yapılacağı mekanik sistemin kaidelerinden sökülmeden ve dışarıdan bir ikaz vermeden çalışma şartlarında efektif olarak modal karakteristiklerinin belirlenebileceği gösterilmiştir. Aşağıda verilen literatür taramasında genel olarak jeneratörlerin dinamiği ve operasyonel modal analizi ile ilgili birtakım çalışmalardan bahsedilmiştir.

H. Clarke ve arkadaşları, operasyonel modal analiz yöntemini (OMA) alternatör setlerinin titreşim karakteristiklerinin belirlenmesinde etkili bir yöntem olarak kullanmışlardır. Ölçümler, çalışma ortamı esnasındaki ikaz şartlarında elde edilmiştir. Özellikle kalkma ve durma esnasında alınan kısa zaman datası, mod şekillerinin belirlenmesi açısından en önemli veriyi sağlamıştır. Çalışmada $5 \mathrm{~Hz}$ ile $180 \mathrm{~Hz}$ arasında birçok rijit cisim modu ve elastik modlar tespit edilmiştir. Çalışılan alternatör setleri arasında yüksek düzeyde korelasyon gözlemlenmiştir [2]. B. Peeters ve G. De Roeck, çalışmalarında, referans sensörlerinin önceden sistem tanımlama adımında bulunmasını esas alan ve yeni bir olasılıksal altuzay tanımlama yaklaşımı adımı olan "yeni alınan çıktıların yatay uzayının eski alınan referans çıktılarının yatay uzayının üzerine izdüşümünü almak" prensibini irdelemişlerdir. Ayrıca çalışma şartlarında yapılan testlerde tipik olarak görülen "tüm serbestlik derecelerinden aynı anda ölçüm alınamama fakat üstüste çakışan referans sensörleri ile parçalı halde ölçüm alınabilmesi" prensibinden de bahsedilmiştir. Bu referans sensörlerinin özellikle global mod şekillerinin elde edilmesi için gerekli olduğu üzerinde durulmuştur [3]. Y. Yang ve S. Nagarajaiah, kör kaynak ayrıştırma tabanlı yöntemlerin salt çıktı temelli modal analizler için çok etkin ve güçlü olduğunu göstermişlerdir. Günümüzde varolan kör kaynak ayrıştırma tabanlı yöntemlerin ölçüm için en az aktif mod sayısı kadar sensör gerektirdiği bilinmektedir. Bu çalışmada, yeni bir kör kaynak ayrıştırma tabanlı yöntem olan ve "ayrık bileşen analizi” adı verilen bir modal analiz algoritması önerilmektedir. Bu analiz yönteminde, aktif mod sayısından oldukça düşük sayıda sensör kullanılmakta olup yöntemin sınırlı sayıda sensör ile yapılabilen çok güvenilir, basit ve etkin bir salt çıktı temelli modal analiz olduğu ortaya konulmuştur [4]. R. Brincker ve arkadaşları, özellikle ikaz sisteminin bilinmediği durumlardaki modal parametrelerin tahmin edilmesinin gerektiği zamanlarda kullanılmak üzere frekans 
bazında yeni bir modal tanımlama tekniği sunmaktadırlar. Sunulan teknik, klasik yöntem olan "modal parametrelerin tepe noktalarından elde edilmesi" yöntemine çok benzerdir. Ancak, cevap spektrumları, spektral yoğunluk fonksiyonu matrisinin ayrıştırılması yöntemiyle herbiri ayrı bir moda karşılık gelecek şekilde bir dizi tek serbestlik dereceli sisteme ayrılabilir. Bu ayrıştırma tekniği ile sinyalde yüksek gürültü kirliliği olsa bile birbirine yakın modlar yüksek hassasiyet ile elde edilebilir. Ayrıca bu yöntem, cevap sinyali içindeki harmonik bileşenleri bariz bir şekilde gösterebilmektedir [5]. R. Brincker, çalışmasında, operasyonel modal analiz yapmak isteyen araştırmacılar için bir kaynak oluşturması amacıyla operasyonel modal analizin belli başlı bileşenlerine genel bir bakış sunmuştur. Çalışma, genel olarak rastgele titreşim cevabı modellemesi ile Fourier serileri, Fourier integrali, Laplace dönüşümü ve Z-dönüşümü gibi operasyonel modal analiz dönüşümlerine yer vermiştir. Ayrıca çalışmada, rastgele titreşim cevabı spektral yoğunluk matrisi ile beyaz gürültü altında korelasyon fonksiyonu ve spektral yoğunluk matrisinin teorik çözümlerine yer verilmiştir. Bunun yanında deneysel çalışmalar için birtakım önemli öneriler ve çokça kullanılan sinyal işleme teknikleri üzerinde durulmuş olup birtakım zaman kümesi ve frekans kümesi tanımlama teknikleri ile ilgili çeşitli algoritmalar sunularak mod şekli ölçeklendirme ve mod şekli genişletme konuları irdelenmiştir [6]. J. Grosel ve arkadaşları, çeşitli mühendislik yapıları bazında, klasik modal analiz ile operasyonel modal analiz yöntemlerinin karşılaştırılması üzerinde çalışmışlardır. Çalışmada, çeşitli mühendislik yapıları üzerinde uygulanan titreşim ölçümlerinin sonuçları farklı birtakım veri işleme teknikleri ile beraber sunulmuştur. Titreşim ölçümleri, kendi çalışmamızda olduğu gibi Brüel \& Kjær firması tarafından üretilmiş olan çok kanallı PULSE ölçüm ve analiz sistemiyle gerçekleştirilmiştir [7]. E. P. Carden ve M. Lindblad, elektrik motoru ile sürülen bir pistonlu kompresör, dizel motor ile sürülen bir su pompası ve bir gemi itici sistemi üzerinde burulma modlarının tespiti için uygulanan bir operasyonel modal analiz çalışması gerçekleştirmişlerdir. Rotor sistemlerinde, eğilme modlarının tersine burulma modlarının hıza bağlı olmadığ1 görülmüştür. Bunun sebebinin, burulma modlarının farklı yükleme durumlarında farklı biçimlerde olmasından kaynaklandığı düşünülmüştür [8]. J. Johansson ve arkadaşları, çalışmalarında, 2 kutuplu dönen makinalar üzerinde birtakım operasyonel modal analizler sunmaktadırlar. Analiz frekans aralığı 50 ile $100 \mathrm{~Hz}$ arası olarak belirlenmiş olup, dengelenmemiş yüklerin ve elektromanyetik kuvvetlerin, stator üzerinde yüksek titreşim genlikleri ortaya çıkardığı gözlemlenmiştir. Çalışmada, biri "Eğri Uydurulmuş Frekans Kümesi Ayrıklaştırması", diğeri ise "Olasılıksal Altuzay Sistem Tanımlama" yöntemi olmak üzere iki analiz yöntemi kullanılmıştır. Bu yöntemlerle elde edilen sonuçlar aynı zamanda klasik modal analiz yöntemiyle elde edilen sonuçlarla karşılaştırılmış ve sonuçlar irdelenmiştir [9]. E. P. Carden, çalışmasında, bir açık deniz platformu üzerine yerleştirilmiş dizel jeneratörün çeşitli bileşenleri üzerinde oluşan hasar ve çatlakları incelemiştir. İncelenen dizel jeneratör, yanyana monte edilmiş birbiri ile aynı boyutlara sahip 5 adet yapıdan bir tanesini oluşturuyordu. Çatlakların oluştuğu birim en yüksek titreşimin olduğu birimdi. Çalışmada, birimlerin hizalamalarının iyileştirilmesi, kaidelerin güçlendirilmesi ve hasarlı noktaların tamiri gibi işlemlerin hiçbirinin hasarların tekrar oluşmasına engel olmadığı gösterilmiştir. Ölçümler işletme şartlarında alınmış olup elde edilen zaman datası üzerinde operasyonel modal analiz gerçekleştirilmiştir. Analiz sonuçları irdelendiğinde, problemin yapıların farklılıklarından değil alternatör içindeki yapısal bir kusurdan kaynaklandığı sonucuna varılmıştır [10]. J. Bednarz öncelikle operasyonel modal analiz metodunda, ikazın rastgele olduğu kabulünü yaparak işe başlamıştır. Fakat bu kabulün, operasyonel modal analizle (OMA) elde edilen modal modelin doğruluğunu kötü yönde etkileyen ve ikazın dönen bileşenlerden geldiği birtakım endüstriyel makinalarda geçerli olmadığı da belirtilmiştir. Bu yüzden bu 
problemin aşılmasını sağlayan tekniklerin elde edilmesi büyük önem arz etmektedir. Çalışmada, bu tekniklerden biri olan OMAX metodunun, mekanik yapıların operasyonel şartlarda incelenmesinde günümüzde sıklıkla kullanılan bir metod olduğu belirtilmektedir. Çalışma genel olarak klasik operasyonel modal analiz (OMA) ile OMAX yönteminin karşılaştırılmasını içermektedir [11].

\section{Amaç ve kapsam}

Bilindiği üzere, "Çalışma Şartlarında Modal Analiz" olarak da adlandırılan "Operasyonel Modal Analiz (OMA)", ikaz durumunun veya ikaz kuvvetlerinin bilinmediği şartlarda makina çalışırken veya bir dış ikaz altındayken toplanan titreşim zaman verisi yardımıyla yapılan deneysel bir modal analiz yöntemidir. Bulunduğu kaideden veya ortamdan sökülmeden varolan ikaz şartlarında yapılan bu analiz yöntemi ile klasik modal analiz yönteminde olduğu gibi yapının tüm modal parametreleri (doğal frekansları, mod şekilleri ve sönüm oranları) elde edilebilir. Ancak jeneratör, pompa, pervane vb. gibi dönen bileşenler içeren sistemlerin analiz sonuçlarında "harmonikler" adı verilen bileşenler de ortaya çıkar. Operasyonel modal analiz sonuçlarını elde ederken mevcut veriyi bu harmoniklerden ayrıştırmaya gerek duyulmaktadır. Bunun için ya analiz sırasında incelenen yapının dönen bileșenlerinin durdurulması ya da ona uygun bir yazılım kullanılması gerekmektedir. Şekil 1'de bu çalışmada incelenen jeneratör setinin gemi makina dairesinin zeminine bağlanmış hali gösterilmektedir.

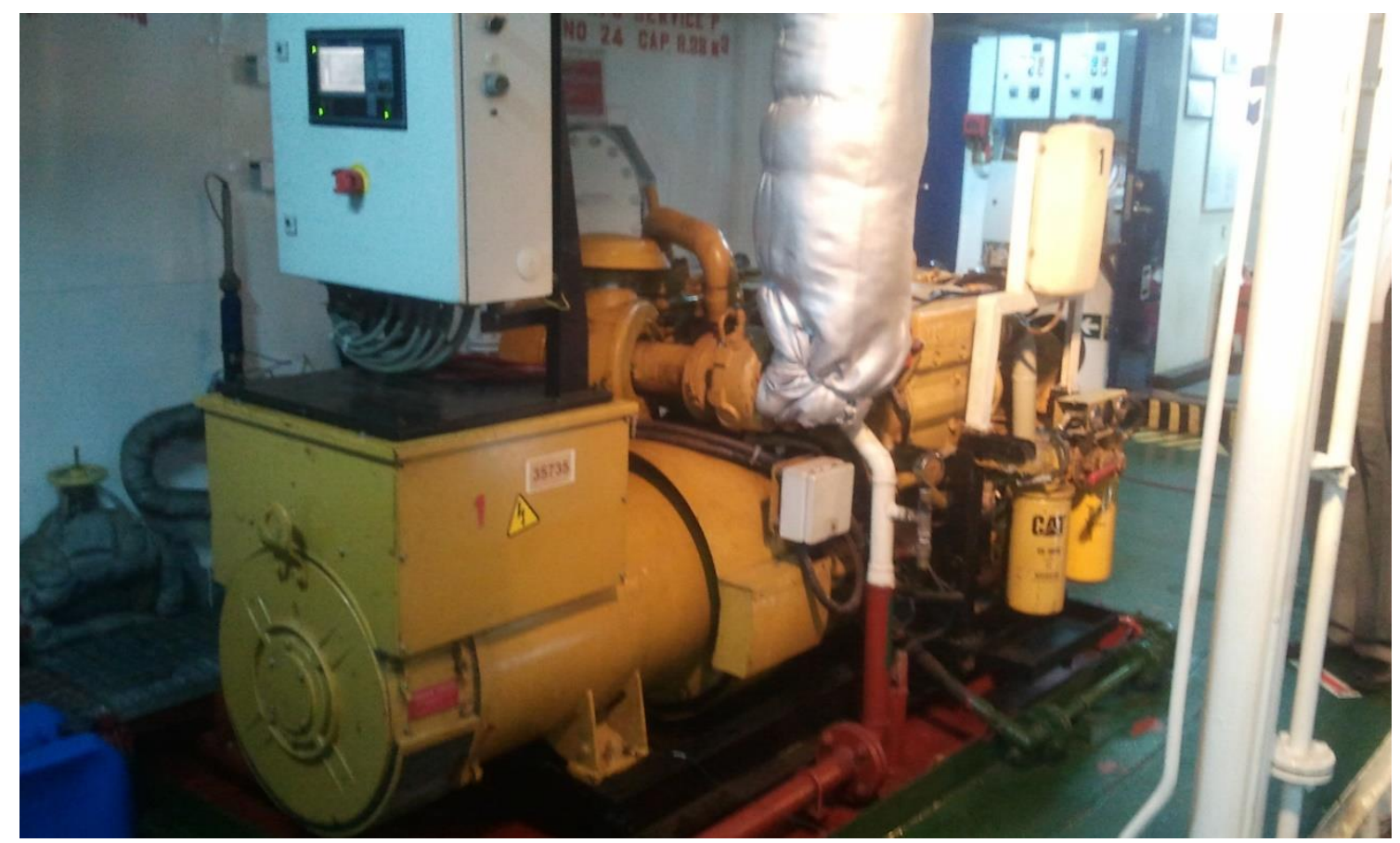

Şekil 1. Modal analizi yapılan gemi jeneratör seti.

Analizi yapılan gemi jeneratör seti, "Caterpillar C9Di" marka bir dizel gemi jeneratör setidir. Jeneratör seti, İstanbul/Tuzla tersaneler bölgesinde bulunan "ÇINDEMİR" tersanesinde havuzlanmış "UĞUR DADAYLI" adlı geminin makina dairesinin zeminine bağlanmış durumdadır. Çalışmada kullanılan jeneratör setinin teknik özellikleri Tablo 1 'de belirtilmiştir. 
Tablo 1. Caterpillar dizel jeneratör setinin teknik özellikleri.

\begin{tabular}{|c|c|}
\hline Özellik & Değer \\
\hline Model & C9Di \\
\hline Maksimum Güç & 375 BG \\
\hline Minimum Güç & 275 BG \\
\hline Maksimum Tork & 1667 Nm (1400 rpm) \\
\hline Silindir Sayısı & $6($ siralı) \\
\hline Nominal Devir Sayısı & $1800 \mathrm{rpm}$ \\
\hline
\end{tabular}

\section{Modal analiz}

Jeneratör setinin operasyonel modal analizini gerçekleştirmek için 2 adet ivmeölçer (piezoelektrik sensör) kullanılmıştır. Bunlardan biri referans sensörü diğeri ise gezici sensördür. Referans sensörü olarak Brüel \& Kjær firmasının 4506-B modeli olan 50 $\mathrm{mV} / \mathrm{ms}^{-2}$ hassasiyetinde, üç eksenli piezoelektrik sensörü ile gezici sensör olarak yine Brüel \& Kjær firmasının 4507-B modeli olan $10 \mathrm{mV} / \mathrm{ms}^{-2}$ hassasiyetinde, tek eksenli piezoelektrik sensörü kullanılmıştır. Operasyonel modal analizin gerçekleştirilebilmesi için yine Brüel \& Kjær firması tarafindan geliştirilmiş "PULSE Operational Modal Analysis" yazılımından faydalanılmıştır. Öncelikle jeneratör setinin PULSE OMA yazılımı üzerinde, modal modelinin oluşturulması ve referans noktası ile gezici sensörle veri toplanacak düğüm noktalarının tanımlanması yapılmıştır. Örnekleme frekansının tespiti için ise $\mathrm{f}_{\text {ör }}$ örnekleme frekansı ve $f_{\text {max }}$ görmek istediğimiz en yüksek frekans değeri olmak üzere,

$\mathrm{f}_{\text {ör }}>(2.4) \mathrm{f}_{\max }$

bağıntısı kullanılmıştır. Şekil 2'de ölçüm için çizilen modal model, Şekil 3'te ise tek eksenli gezici sensörün konumlandırılacağı düğüm noktaları ile ölçüm doğrultuları gösterilmiştir.

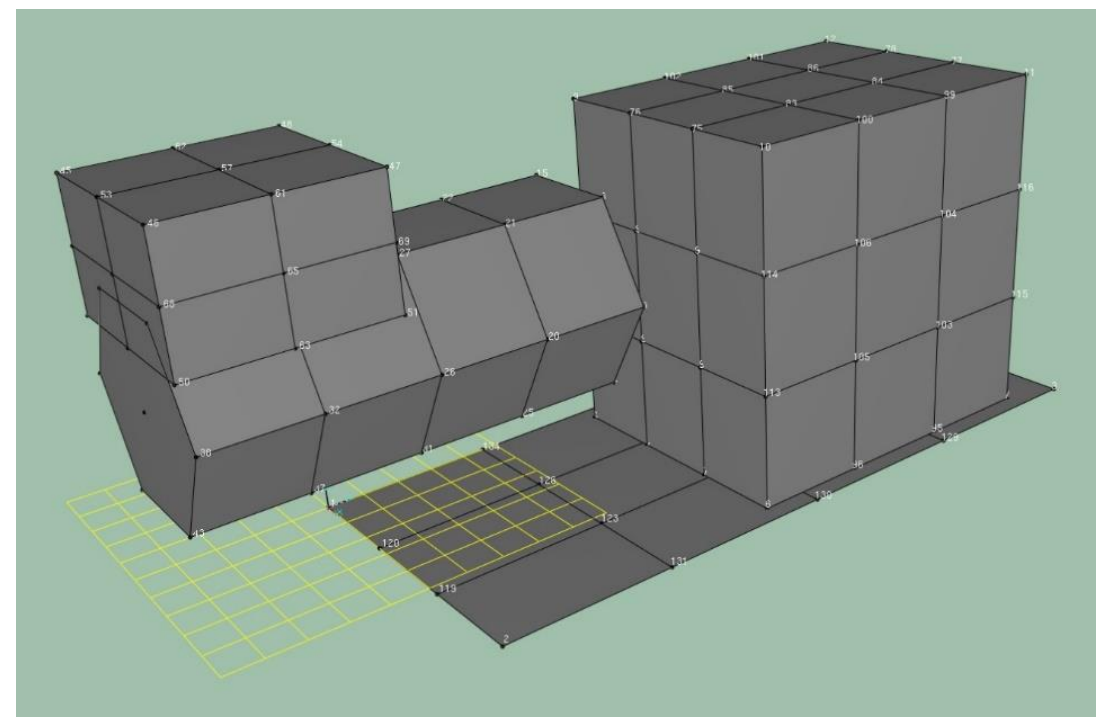

Şekil 2. Modal model. 


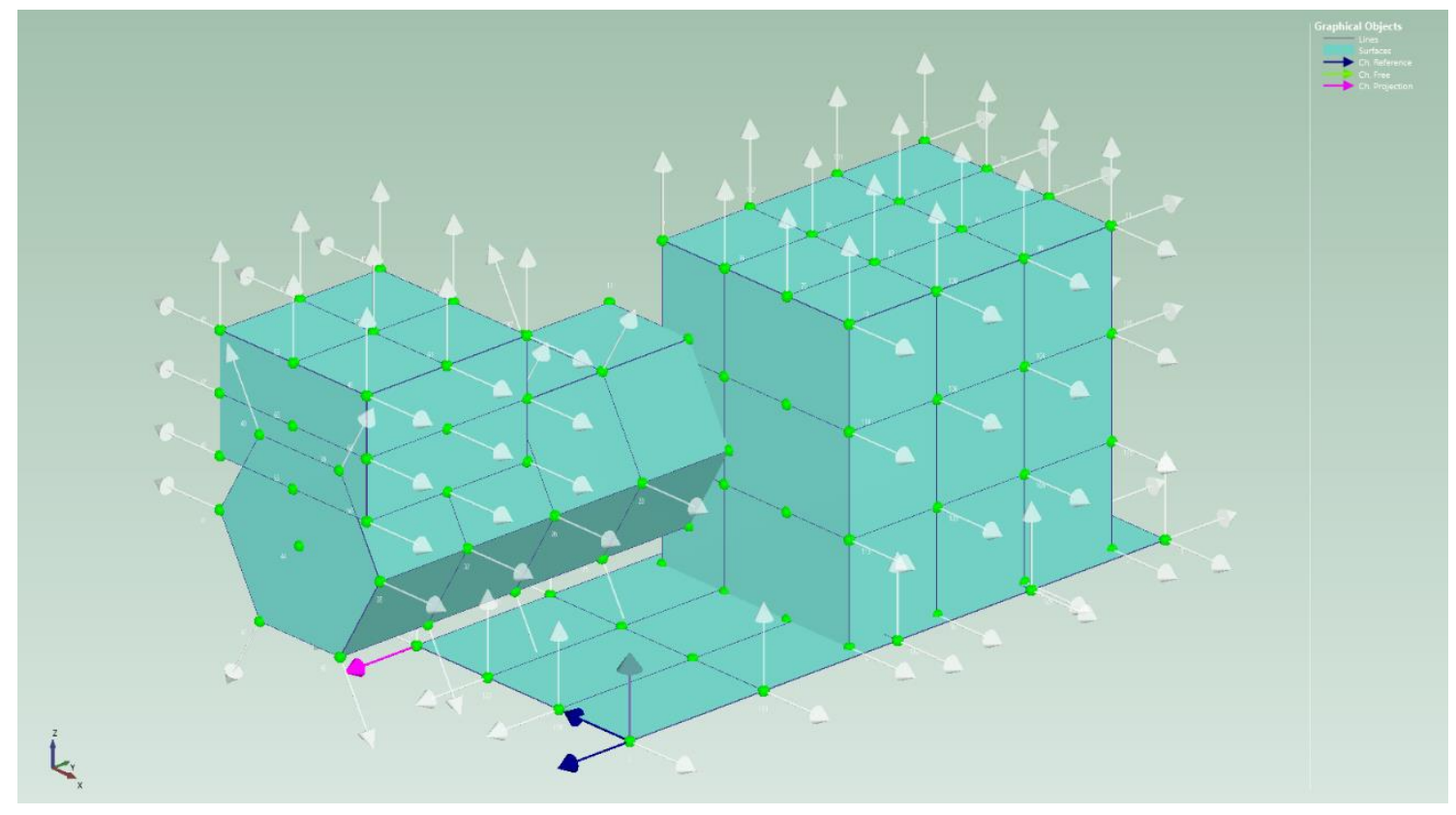

Şekil 3. Modal düğüm noktaları ve ölçüm yönleri.

Modelde toplam 134 düğüm noktası bulunmakta olup deney sonucunda toplam 150 zaman verisi seti elde edilecektir. Zaman verisi seti sayısının dügüm noktası sayısından fazla olmasının sebebi, tek eksenli gezici sensörün bazı düğüm noktalarında ve geometrinin el verdiği ölçüde iki farklı doğrultuda ölçüm alınacak olmasıdır. 2 numaralı düğüm noktası referans noktası olup (mavi eksen takımı) bu düğüm noktasına üç eksenli referans sensörü sabitlenmiştir. Şekil 4'te referans sensörünün konumu gösterilmiştir.

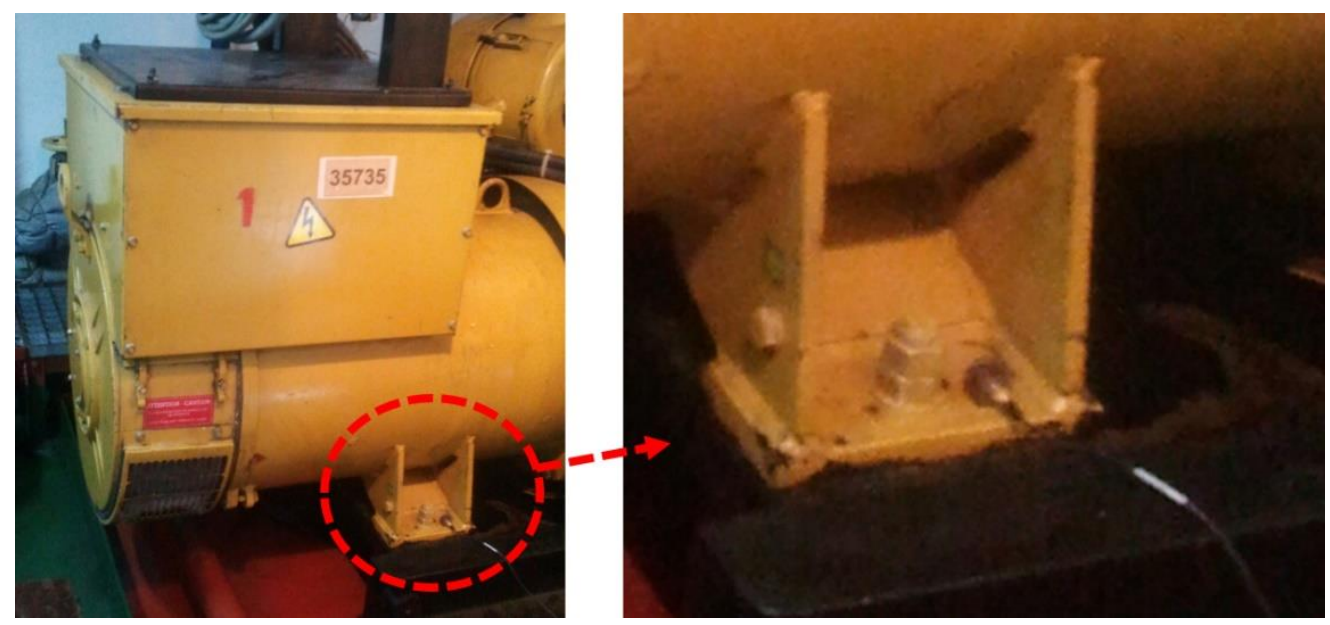

Şekil 4. Referans sensörünün konumu.

Ölçümler şu şekilde alınmıştır. Her ölçümde, analizörün ilk üç kanalından 2 numaralı düğüm noktasına yerleştirilmiş referans sensörünün $\mathrm{x}, \mathrm{y}$ ve $\mathrm{z}$ bileşenlerinin zaman verisi alınırken aynı anda başka bir düğüm noktasına yerleştirilmiş tek eksenli gezici sensörün zaman verisi analizörün dördüncü kanalından alınmıştır. Gezici sensör sırasıyla tüm düğüm noktalarına konuşlandırılarak yukarıda belirtilen zaman verisi kayıtları her düğüm noktası için toplanmıştır. Bu şekilde elde edilen toplam 150 veri seti "PULSE Operational Modal Analysis" yazılımı üzerinde analiz edilerek Şekil 5'te gösterilen “Tekil Değerlere Ayrıştırılmış Spektral Yoğunluklar” grafiği elde edilmiştir. 


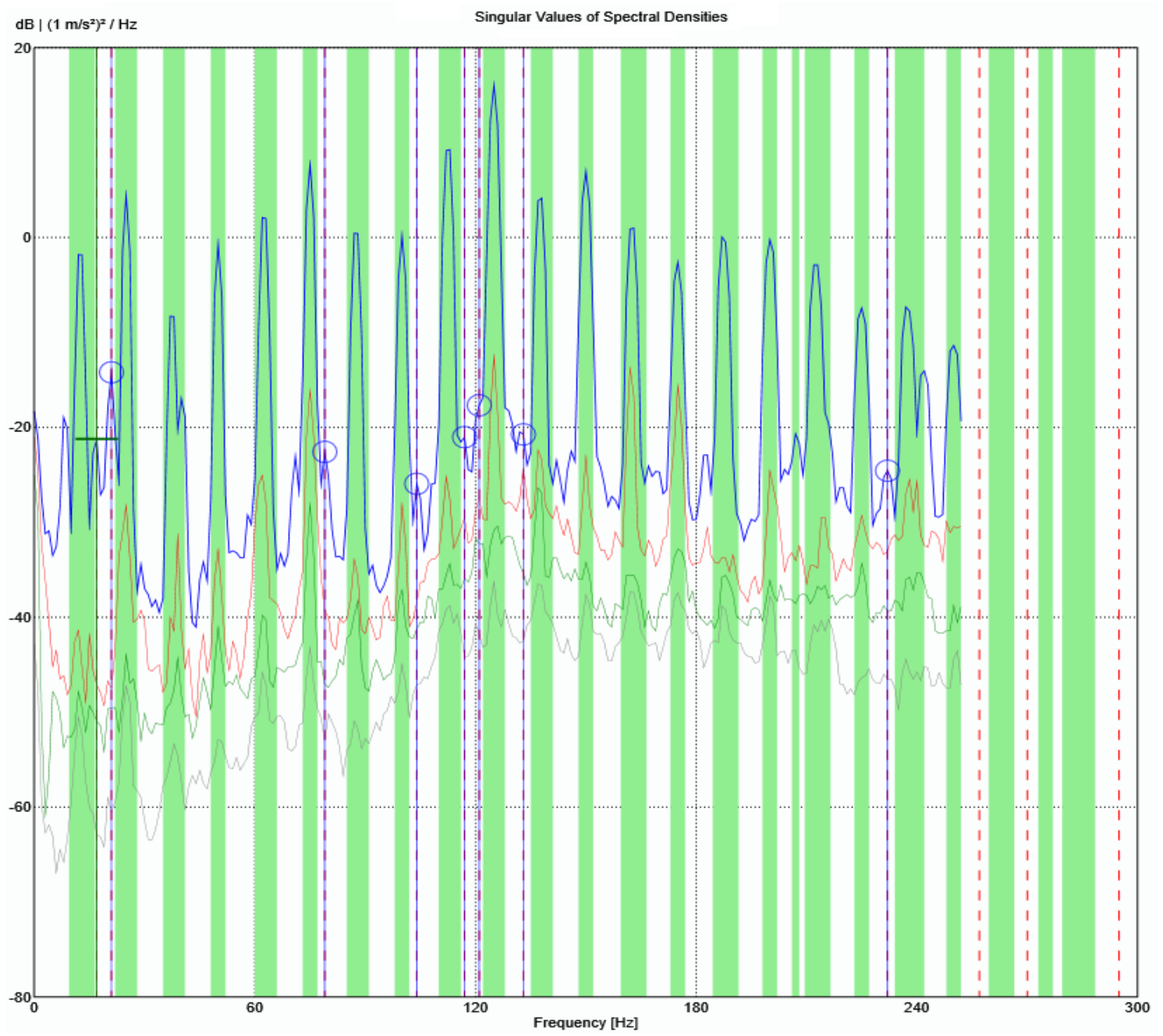

Şekil 5. Tekil değerlere ayrıştırılmış spektral yoğunluklar grafiği.

Bu grafikte, yeşil bölgeler içinde gösterilen tepe noktaları harmonikleri göstermektedir. $\mathrm{Bu}$ yüzden geçerli tahmin fonksiyonu (kesikli dikey kırmızı çizgiler) üzerindeki tepe noktaları bize doğal frekansları vermektedir. Şekil 5'te gösterilen "Tekil Değerlere Ayrıştırılmış Spektral Yoğunluklar” grafiği sonucu elde edilen ilk 10 doğal frekans değeri Tablo 2'de verilmiştir.

Tablo 2. Doğal frekanslar.

\begin{tabular}{|c|c|}
\hline Mod No. & Frekans Değeri (Hz) \\
\hline 1 & 17 \\
\hline 2 & 21 \\
\hline 3 & 79 \\
\hline 4 & 104 \\
\hline 5 & 117 \\
\hline 6 & 121 \\
\hline 7 & 133 \\
\hline 8 & 232 \\
\hline 9 & 257 \\
\hline 10 & 270 \\
\hline
\end{tabular}


Ayrıca, Şekil 6 ve Şekil 7’de, $21 \mathrm{~Hz}$ ve $270 \mathrm{~Hz}$ değerlerindeki mod şekilleri de gösterilmiştir.

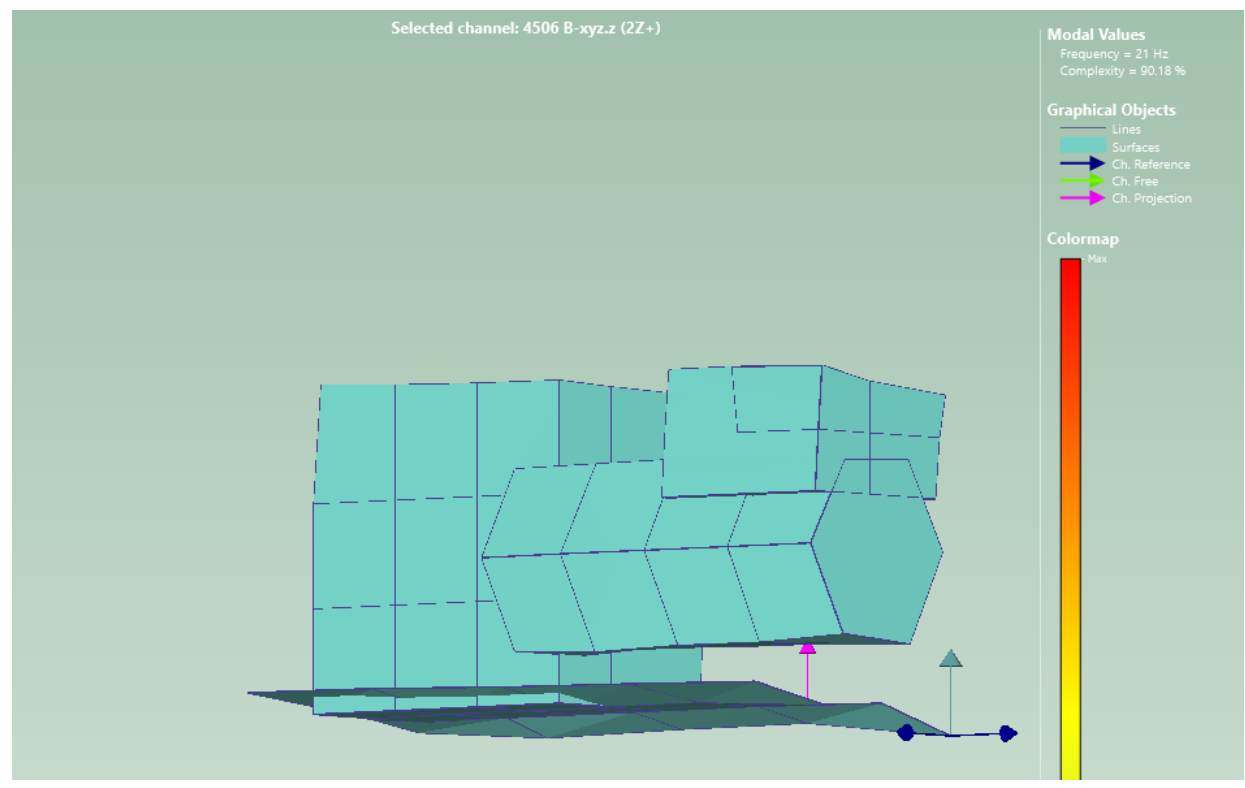

Şekil 6. $21 \mathrm{~Hz}$ değerindeki mod şekli.

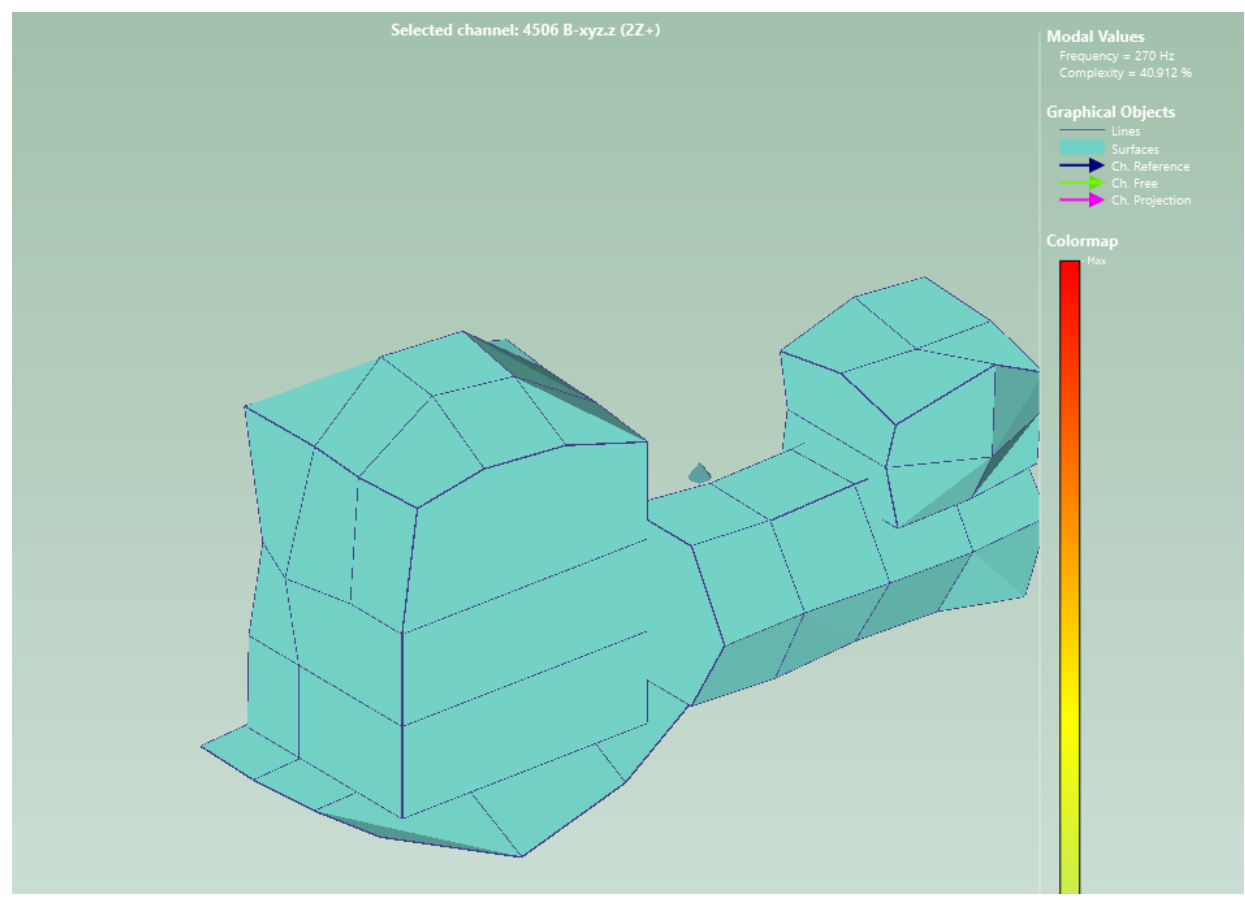

Şekil 7. $270 \mathrm{~Hz}$ değerindeki mod şekli.

Mod şekilleri detaylı incelendiğinde, dönen aksamın ve genel sistemin muhafazası olarak modellenen üst ve alt bölümlerde yüksek düzeyde şekil değişimi ortaya çıktığ1 gözlemlenmiştir. Bunlar şişme modları olarak da adlandırılmaktadırlar. Özellikle yüksek frekans değerlerinde şekil değişimlerinin düşük modlara nazaran daha yüksek olduğu açık olarak görülmektedir. Mod şekillerinde ciddi açıdan bir eğilme ve burulma modu gözlemlenmemiştir. 


\section{Sonuç ve değerlendirme}

Bu çalışmada, ikaz kuvvetleri gözetilmeden doğrudan çalışma şartlarında alınan titreşim zaman verisi üzerinden yapılan ve deneysel bir modal analiz yöntemi olan operasyonel modal analiz yöntemi, havuzlanmış bir geminin makina dairesine kurulmuş bir dizel gemi jeneratör seti üzerinde uygulanmıştır. Çalışma, uygulama alanına bakıldığında ilk defa yapılan bir çalışma olma özelliği taşımaktadır. Gemi titreşim problemlerinde önemli bir titreşim kaynağı olarak görülen jeneratör titreşimlerinin gemi üstyapısı üzerindeki etkilerinin incelenmesinde, bir kaide üzerine oturtulmuş olarak zemine bağlanmış jeneratör setinin doğal frekanslarının hesabı büyük önem taşımaktadır. Bu analiz yöntemi, bulunduğu hacimde ve şartlarda ikaz kuvvetlerinin tespitinin mümkün olmaması durumunda modal parametrelerin hesabında önemli bir yenilik olarak göze çarpmaktadır.

Çözüm için kullanılan tekil değerlere ayrıştırılmış spektral yoğunluklar grafiği, hem harmonikleri hem de doğal frekansları istenilen frekans aralığı içinde detaylı bir şekilde vermektedir. Ayrıca tüm modal parametrelerin elde edilebilmesi için sadece 2 ivmeölçer ve 4 kanallı bir analizör yeterli olmuştur. Yöntemin en büyük özelliği, analiz için sistemin devre dışı bırakılmasına gerek duyulmamış olmasıdır.

Geleceğe yönelik bir çalışma olarak jeneratör setinin sonlu elemanlar analizinin de yapılarak deneysel sonuçlarla karşılaştırılması deneysel çıktıların doğrulanması açısından faydalı bir çalışma olacaktır.

\section{Kaynaklar}

[1] Guidance Notes on Ship Vibration, American Bureau of Shipping, (2006).

[2] Clarke, H., Stainsby, J. ve Carden, E. P., Operational modal analysis of resiliently mounted marine diesel generator/alternator, Proceedings, Conference Proceedings of the Society for Experimental Mechanics Series, Rotating Machinery, Structural Health Monitoring, Shock and Vibration, 5, 237-244, New York, (2011).

[3] Peeters, B., ve De Roeck, G., Reference-based stochastic subspace identification for output-only modal analysis, Mechanical Systems and Signal Processing, 13, 6, 855-878, (1999).

[4] Yang, Y. ve Nagarajaiah, S., Output-only modal identification with limited sensors using sparse component analysis, Journal of Sound and Vibration, 332, 19, 4741-4765, (2013).

[5] Brincker, R., Zhang, L. ve Andersen, P., Modal identification of output-only systems using frequency domain decomposition, Smart Materials and Structures, 10, 3, 441-445, (2000).

[6] Brincker, R., Some elements of operational modal analysis, Proceedings, International Conference on Structural Engineering Dynamics, 2014, (2013).

[7] Grosel, J., Sawicki, W. ve Pakos, W., Application of classical and operational modal analysis for examination of engineering structures, Procedia Engineering, 91, 136-141, (2014).

[8] Carden, E. P. ve Lindblad, M., Operational modal analysis of torsional modes in rotating machinery, The Journal of Engineering for Gas Turbines and Power, 137, 2, (2015). 
[9] Johansson, J., Samuelsson, H., Jacobsen, N. J. ve Angantyr, A., Operational modal analysis of large 2-pole rotating machinery, Proceedings, 3rd International Operational Modal Analysis Conference, Portonovo, Italy, (2009).

[10] Carden, E. P., Investigation of offshore diesel generator failure using operational modal analysis, Proceedings, 5th International Operational Modal Analysis Conference, Guimarães, Portugal, (2013).

[11] Bednarz, J., Example of the application of operational modal analysis method for damage detection of the rotating blades, Vibroengineering Procedia, 6, 45-49, (2015). 